\title{
De-Escalation of Antiplatelet Treatment in Patients with Myocardial Infarction Who Underwent Percutaneous Coronary Intervention: A Review of the Current Literature
}

\author{
Daniel MF Claassens ${ }^{1, *(1)}$ and Dirk Sibbing ${ }^{2,3,4}$ \\ 1 Department of Cardiology, St. Antonius Hospital, 3435CM Nieuwegein, The Netherlands \\ 2 Privatklinik Lauterbacher Mühle am Ostersee, 82402 Iffeldorf, Germany; \\ Dirk.Sibbing@med.uni-muenchen.de \\ 3 Department of Cardiology, Klinikum der Universität München, Ludwig-Maximilians-University, \\ 81377 Munich, Germany \\ 4 DZHK (German Centre for Cardiovascular Research), Partner Site Munich Heart Alliance, \\ 80802 Munich, Germany \\ * Correspondence: d.claassens@antoniusziekenhuis.nl
}

Received: 19 August 2020; Accepted: 11 September 2020; Published: 15 September 2020

\begin{abstract}
In acute coronary syndrome (ACS) patients undergoing percutaneous coronary intervention (PCI), treatment with the $\mathrm{P}_{2} \mathrm{Y}_{12}$ inhibitors ticagrelor or prasugrel is recommended over clopidogrel due to a better efficacy, albeit having more bleeding complication. These higher bleeding rates have provoked trials investigating de-escalation from ticagrelor or prasugrel to clopidogrel in the hope of reducing bleeding without increasing thrombotic event rates. In this review, we sought to present an overview of the major trials investigating several different options for de-escalation; unguided, platelet function testing- and genotype-guided. Based on these results, and on other established literature sources, such as guidelines and expert consensus papers, we provide an overview to help decide when and how to de-escalate antiplatelet therapy in ACS patients undergoing PCI.
\end{abstract}

Keywords: $\mathrm{P} 2 \mathrm{Y}_{12}$ inhibitor; clopidogrel; ticagrelor; prasugrel; de-escalation; platelet function testing; genotype-guided; percutaneous coronary intervention; acute coronary syndrome; myocardial infarction

\section{Introduction}

Patients with myocardial infarction and percutaneous coronary intervention (PCI) require dual antiplatelet therapy (DAPT) consisting of aspirin and a P2Y 12 inhibitor for at least 6 to 12 Months [1,2] In patients with myocardial infarction, potent platelet inhibition with ticagrelor or prasugrel instead of clopidogrel has been preferred by the major guidelines in the past decade. These recommendations followed after results of the Platelet Inhibition and Patient Outcomes (PLATO) and the Trial to Assess Improvement in Therapeutic Outcomes by Optimizing Platelet Inhibition With Prasugrel Thrombolysis in Myocardial Infarction 38 (TRITON-TIMI 38) trials, demonstrated a reduction in thrombotic events in patients using ticagrelor and prasugrel compared to clopidogrel, and the U.S. Food and Drug Administration (FDA) added a boxed warning regarding the reduced effectiveness of clopidogrel in poor metabolizers [3,4]. However, the increased efficacy of the potent $\mathrm{P}^{2} \mathrm{Y}_{12}$ inhibitors is hampered by a higher bleeding risk.

Clopidogrel is a prodrug. The active metabolite irreversibly binds to the $\mathrm{P}_{2} \mathrm{Y}_{12}$ receptor on platelets leading to reduced platelet activation [5]. Patients on clopidogrel demonstrate a wide 
variability in platelet reactivity and approximately $30 \%$ of the patients have an inadequate reduction in platelet reactivity measured using platelet function testing [6]. The most important enzyme in the activation process is encoded by the CYP2C19 gene. This gene has many different alleles, some of which are considered loss-of-function alleles and can be present in more than $30 \%$ of the population [7]. Patients carrying loss-of-function alleles generally show higher residual platelet reactivity and are at an increased risk for thrombotic events $[8,9]$.

\section{De-Escalation of Antithrombotic Therapy}

The higher risk of bleeding in patients on potent $\mathrm{P} 2 \mathrm{Y}_{12}$ inhibitors remains present in the chronic treatment phase, while the greatest benefit of the potent drugs are seen early, when the risk of recurrent thrombotic events is highest $[10,11]$. De-escalation is the process of switching from the potent $\mathrm{P}_{2} \mathrm{Y}_{12}$ inhibitors prasugrel or ticagrelor to weaker clopidogrel. Despite a lack of evidence supporting de-escalation, de-escalation is common in clinical practice and occurs in up to $30 \%$ of patients with myocardial infarction [12-14]. This is triggered by both clinical factors (e.g., side effects like dyspnea or (minor) bleedings) and socioeconomic factors (e.g., higher costs of ticagrelor and prasugrel treatment) [12-14]. For instance, in the Comparison of Prasugrel and Ticagrelor in the Treatment of Acute Myocardial Infarction (PRAGUE-18) trial, more than one-third of patients de-escalated to clopidogrel for economic reasons [12], while in the POPular AGE trial (including acute coronary syndrome (ACS) patients of 70 years and older), treatment adherence in the ticagrelor and prasugrel group was just 53\% during the one year follow-up, mainly due to side effects and a perceived high bleeding risks [13].

This has prompted many observational studies investigating the effects of de-escalation of antiplatelet therapy [15], but in the last few years different randomized controlled trials have been published as well [16-18]. These trials investigated several different methods of de-escalation; unguided de-escalation, platelet function testing (PFT)-guided de-escalation and genotype-guided de-escalation. For this review, we focus on randomized controlled trials that investigate de-escalation from ticagrelor or prasugrel to clopidogrel. Results are summarized in Table 1.

Table 1. Major randomized clinical trials investigating de-escalation of $\mathrm{P}_{2} \mathrm{Y}_{12}$ inhibitor treatment in patients with ACS.

\begin{tabular}{|c|c|c|c|}
\hline Table Header & TOPIC & TROPICAL-ACS & POPular Genetics \\
\hline Study Size & $n=646$ & $n=2610$ & $n=2488$ \\
\hline Population & ACS + PCI (40\% STEMI) & (N)STEMI + PCI (55\% STEMI) & $\begin{array}{l}\text { STEMI + primary PCI } \\
(100 \% \text { STEMI })\end{array}$ \\
\hline Timing of De-Escalation & 1 Month After ACS & 7 Days After Discharge & 1-3 Days After Primary PCI \\
\hline Method of De-Escalation & Unguided & PFT-Guided & Genotype-Guided \\
\hline Study Design & $\begin{array}{l}\text { Single-Center, Randomized, } \\
\text { Open-Label Trial of } \\
\text { Unguided De-Escalation Vs. } \\
\text { Standard Treatment }\end{array}$ & $\begin{array}{l}\text { Randomized, Open-Label, } \\
\text { Non-Inferiority Trial Of } \\
\text { PFT-Guided De-Escalation Vs. } \\
\text { Standard Treatment }\end{array}$ & $\begin{array}{l}\text { Randomized, Open-Label, } \\
\text { Non-Inferiority Trial of } \\
\text { Genotype-Guided De-Escalation } \\
\text { Vs. Standard Treatment }\end{array}$ \\
\hline Control Arm & $\begin{array}{c}\text { Ticagrelor/Prasugrel for } \\
12 \text { Months }\end{array}$ & Prasugrel for 12 Months & $\begin{array}{c}\text { Ticagrelor/Prasugrel for } \\
12 \text { Months }\end{array}$ \\
\hline Experimental Arm & $\begin{array}{c}1 \text { Month of } \\
\text { Ticagrelor/Prasugrel } \\
\text { Followed By } 11 \text { Months of } \\
\text { Clopidogrel }\end{array}$ & $\begin{array}{c}\text { PFT-Guided De-Escalation } \\
\text { With } 1 \text { Week Prasugrel } \\
\text { Followed By } 1 \text { Week } \\
\text { Clopidogrel, Then Depending } \\
\text { on PFT Results Clopidogrel Or } \\
\text { Prasugrel From Day } 14 \text { To } \\
12 \text { Months }\end{array}$ & $\begin{array}{c}\text { CYP2C19 Genotyping } \\
\text { Immediately After Primary PCI. } \\
\text { Non-Carriers of loF Alleles } \\
\text { Switched to Clopidogrel As } \\
\text { Soon As Possible, Carriers } \\
\text { Continued Ticagrelor/Prasugrel } \\
\text { for } 12 \text { Months }\end{array}$ \\
\hline
\end{tabular}


Table 1. Cont.

\begin{tabular}{|c|c|c|c|}
\hline Table Header & TOPIC & TROPICAL-ACS & POPular Genetics \\
\hline Primary Endpoint & $\begin{array}{c}\text { 1-Yr Incidence of } \\
\text { Cardiovascular Death, } \\
\text { Unplanned Hospitalization } \\
\text { Leading to Urgent Coronary } \\
\text { Revascularization, Stroke or } \\
\text { BARC } \geq 2 \text { Bleeding }\end{array}$ & $\begin{array}{l}\text { 1-Yr Incidence of } \\
\text { Cardiovascular Death, } \\
\text { Myocardial Infarction, Stroke } \\
\text { or BARC } \geq 2 \text { Bleeding }\end{array}$ & $\begin{array}{l}\text { 1-Yr Incidence of All-Cause } \\
\text { Death, Myocardial Infarction, } \\
\text { Definite Stent Thrombosis, } \\
\text { Stroke or PLATO Major Bleeding }\end{array}$ \\
\hline Key Safety Endpoint & BARC $\geq 2$ Bleeding & BARC $\geq 2$ Bleeding & $\begin{array}{l}\text { PLATO Major and } \\
\text { Minor Bleeding }\end{array}$ \\
\hline Key Findings & $\begin{array}{c}\text { Primary Net Clinical } \\
\text { Benefit Endpoint }(13.4 \% \text { In } \\
\text { De-Escalation Vs. } 26.3 \% \text { In } \\
\text { Control Group; } P<0.01 ; \mathrm{HR} \text { : } \\
0.48,95 \% \text { CI: } 0.34-0.68 \\
\text { Thrombotic Event Rates Of } \\
\text { 9.3\% In De-Escalation Vs. } \\
\text { 11.5\% In Control Group; } \\
P=0.36 \\
\text { Bleeding Event Rates Of } \\
\text { 4.0\% In De-Escalation Vs. } \\
\text { 14.9\% In Control Group; HR } \\
\text { 0.30, 95\% CI: } 0.18-0.50 ; \\
P<0.01\end{array}$ & $\begin{array}{c}\text { Primary Net Clinical Benefit } \\
\text { Endpoint (7.3\% In } \\
\text { De-Escalation Vs. 9.0\% In } \\
\text { Control Group; Pnoninf <0.001; } \\
\text { HR: 0.81, 95\% CI: 0.62-1.06 } \\
\text { Thrombotic Event Rates Of } \\
\text { 2.5\% In De-Escalation Vs. } \\
\text { 3.2\% In Control Group; HR } \\
\text { 0.77, 95\% CI: } 0.48-1.21 ; \\
\text { Pnoninf }=0.01 \\
\text { Bleeding Event Rates Of } 4.9 \% \\
\text { In De-Escalation Vs. } 6.1 \% \text { In } \\
\text { Control Group; HR } 0.83,95 \% \\
\text { CI: } 0.59-1.13 ; P=0.23\end{array}$ & $\begin{array}{c}\text { Primary Net Clinical Benefit } \\
\text { Endpoint }(5.1 \% \text { In } \\
\text { De-Escalation Vs. 5.9\% In } \\
\text { Control Group; P Poninf <0.001; } \\
\text { HR: } 0.87,95 \% \text { CI: } 0.62-1.21 \\
\text { Thrombotic Event Rates Of } \\
\text { 2.7\% In De-Escalation Vs. 3.3\% } \\
\text { In Control Group; HR 0.83, 95\% } \\
\text { CI: } 0.53-1.31 \\
\text { Bleeding Event Rates Of 9.8\% } \\
\text { In De-Escalation Vs. } 12.5 \% \text { In } \\
\text { Control Group; HR } 0.78,95 \% \text { CI: } \\
\text { 0.61-0.98; } P=0.04\end{array}$ \\
\hline Funding & $\begin{array}{l}\text { Investigator Initiated Trial. } \\
\text { Funded by Hôpitaux } \\
\text { De La Timone }\end{array}$ & $\begin{array}{c}\text { Investigator Initiated Trial } \\
\text { Funded by Roche Diagnostics. } \\
\text { Eli Lilly \& Daiichi Sankyo } \\
\text { Company Supported } \\
\text { Prasugrel Purchase and } \\
\text { Drug Delivery }\end{array}$ & $\begin{array}{l}\text { Investigator Initiated Trial. } \\
\text { Funded by Netherlands } \\
\text { Organization for Health } \\
\text { Research and Development. } \\
\text { Spartan Bioscience Provided } \\
\text { Genotyping Equipment for Free }\end{array}$ \\
\hline \multicolumn{4}{|c|}{$\begin{array}{l}\mathrm{ACS}=\text { acute coronary syndrome, } \mathrm{BARC}=\text { bleeding academic research consortium, } \mathrm{CI}=\text { confidence interval, } \\
\mathrm{HR}=\text { hazard ratio, noninf }=\text { non-inferiority, LoF }=\text { loss-of-function, NSTEMI = non-ST-elevation myocardial } \\
\text { infarction, PCI = percutaneous coronary intervention, PFT = platelet function testing, PLATO = Platelet Inhibition } \\
\text { and Patient Outcomes, STEMI = ST-elevation myocardial infarction. }\end{array}$} \\
\hline
\end{tabular}

\section{Unguided De-Escalation}

The Timing of Platelet Inhibition After Acute Coronary Syndrome (TOPIC) trial investigated unguided de-escalation from a potent platelet inhibitor to clopidogrel 1 month after an ACS [16]. It included 646 patients, 323 randomized to de-escalation of DAPT, and 323 to continuing potent platelet inhibition. It found a significant reduction in bleeding academic research consortium (BARC) 2 and higher bleedings $(4.0 \%$ vs. $14.9 \%$ for de-escalated and potent DAPT, respectively, HR 0.30 , $95 \%$ confidence interval (CI) $0.18-0.50$ ), with no difference in thrombotic events, consisting of cardiovascular death, unplanned revascularization and stroke $(9.3 \%$ vs. $11.5 \%$, HR $0.80,95 \%$ CI 0.50-1.29). A pre-specified sub analysis of the TOPIC trial assessed the effect of on-treatment platelet reactivity (on prasugrel or ticagrelor) on clinical outcomes [19]. It found that de-escalation was superior regardless of initial platelet reactivity, but that patients classified as low on-treatment platelet reactivity had the highest risk of experiencing a clinical event (either bleeding or thrombotic) and benefited the most from de-escalation. Though these results seem very promising, several important limitations have to be considered. First, the trial had a small sample size. Second, there was no detailed reporting and external event adjudication on key endpoints and third, a difference in event rates, both thrombotic and bleeding, in favor of de-escalation was already seen prior to actual de-escalation.

The recently published HOST-REDUCE-POLYTECH-ACS was a randomized trial that investigated a different kind of de-escalation. It included 2338 East Asian patients with ACS and PCI who were treated with prasugrel $10 \mathrm{mg}$ daily for one month [20]. After one month, patients were randomized to either $5 \mathrm{mg}$ daily for 11 months or continued $10 \mathrm{mg}$ daily for the rest of the year. It found the reduced dose to be superior for a combined bleeding and ischemic outcome composed of all-cause death, myocardial infarction, stent thrombosis, repeat vascularization, stroke, or bleeding academic research consortium (BARC) grade 2 bleeding or higher (7.2\% vs. $10.1 \%$, hazard ratio (HR) $0.70,95 \%$ CI 0.52-0.92, $p=0.012$ [ [20]. This was driven by a difference in BARC 2 bleeding, with no difference 
in ischemic outcomes. These results are promising, but there are some important limitations, mostly caused by exclusion of patient groups who cannot be treated by $10 \mathrm{mg}$ of prasugrel (history of transient ischemic attack/stroke, Age $\geq 75$ years and weight $<60 \mathrm{~kg}$ ). The mean age was only 59 years and due to the weight restriction and the low weight of Korean women, there were very few women $( \pm 10 \%)$. Furthermore, most ischemic events were repeat revascularization, with all other ischemic endpoints having an incidence of $<1 \%$. In addition, the mean body weight was $72 \mathrm{~kg}$, and it is, therefore, unsure if in other populations with much higher mean body weight, such as American and European populations, the same effect is reached. Similar to this trial, a randomized trial investigating de-escalation from a high dose to a low dose ticagrelor (90 mg vs. $60 \mathrm{mg}$ ) after 1 week until 1 year is ongoing (NCT04255602).

A meta-analysis from Angiolillo et al. pooled observational studies, which studied de-escalation of treatment from ticagrelor to clopidogrel for various reasons [15]. It found a rate of major adverse cardiac events (MACE) (defined as cardiovascular death, myocardial infarction and stroke) of $2 \%$, a rate of cardiovascular death of $2 \%$ and of major bleeding of $1 \%$. Contrary to these results are the results from the Switching from Clopidogrel to New Oral Antiplatelet Agents during Percutaneous Coronary Intervention (SCOPE). It found much higher rates of MACE, mostly driven by higher rates of myocardial infarction and transient ischemic attack/stroke in patients that de-escalated to clopidogrel [21]. However, patients de-escalating were significantly older and more often had a history of transient ischemic attacks and stroke. In addition, the de-escalation group was very small and it is unclear what the timing of events was about de-escalation.

\section{Platelet Function Testing-Guided De-Escalation}

There have been many trials investigating the use of PFT to guide antithrombotic therapy. However, almost all investigated escalation to stronger or more intensified antiplatelet regimes when high platelet reactivity was found [22-24]. An exception to this was the Testing Responsiveness To Platelet Inhibition On Chronic Antiplatelet Treatment For Acute Coronary Syndromes (TROPICAL-ACS) trial, which included 2610 patients and investigated de-escalation from prasugrel to clopidogrel 7 days after hospital discharge in ST-elevation myocardial infarction (STEMI) and non-ST-elevation myocardial infarction (NSTEMI) patients (all comers ACS cohort) who underwent PCI [17]. After 1 week of clopidogrel use, PFT was performed. Patients demonstrating high platelet reactivity switched back to prasugrel, while the other patients remained on clopidogrel until 12 Months after myocardial infarction. Patients in the control arm were treated with prasugrel for 12 months.

The PFT guided group was non-inferior regarding the primary net clinical benefit outcome consisting of cardiovascular death, myocardial infarction, stroke or BARC grade 2 bleeding or higher (7.3\% vs. $9.0 \%$ in the PFT-guided and standard treatment group respectively, $\mathrm{P}_{\text {non-inferiority }}<0.001$. HR $0.81,95 \%$ CI 0.62-1.06) [17]. The PFT guided group was also non-inferior compared to the prasugrel treated group regarding the thrombotic outcome, defined as cardiovascular death, myocardial infarction, and stroke (2.5\% vs. $3.2 \%$ in the de-escalation and prasugrel group respectively, $\mathrm{HR} 0.77,95 \% \mathrm{CI}$ $\left.0.48-1.21, P_{\text {non-inferiority }}=0.012\right)$. Of note, the trial showed numerically lower bleeding events in the guided de-escalation arm (4.9\% vs. $6.0 \%$ BARC 2 or higher bleeding for the de-escalation and prasugrel group, respectively, HR $0.82,95 \%$ CI 0.59-1.13), but this difference failed to reach a level of statistical significance. A pre-specified sub-analysis of the trial assessed the impact of age clinical outcomes following PFT guided de-escalation [25]. It found that PFT guided de-escalation was associated with a significant reduction in the primary outcome in patients aged 70 and younger ( $\mathrm{HR} 0.70,95 \% \mathrm{CI}$ $0.51-0.96, p=0.03$ ), while there was no difference in elderly patients (HR 1.17, 95\% CI 0.69-2.01, $p=0.56$ ). This effect was mainly driven by a reduction in bleeding events in younger patients, while it must be noted that the elderly group contained only 370 patients. The TROPICAL-ACS trial also had an important limitation; the non-inferiority margin was $30 \%$, though in a post-hoc analysis non-inferiority for the primary endpoint was maintained with a non-inferiority margin of $10 \%$. In addition, the PFT guided group had both numerically lower thrombotic and bleeding event rates than the standard 
treatment group. Further limitations included, the sole use prasugrel in the control group and not ticagrelor, excluding patients with a history of stroke, the open-label design and the loss-to-follow-up of $4 \%$ in both arms.

In TROPICAL ACS the Multiplate analyzer was used to determine platelet inhibition [17]. Correlation between different PFTs is not very good and it is therefore unsure if results can be extrapolated to other PFTs than the Multiplate $[6,26]$. However, the guidelines do not endorse a specific PFT and thus leave the option on what PFT to use open.

\section{Genotype-Guided De-Escalation}

The last option to guide $\mathrm{P}_{2} \mathrm{Y}_{12}$ inhibitor therapy is to use $\mathrm{CYP} 2 \mathrm{C} 19$ genetic testing. Similar to PFT, most trials and observational studies investigated escalation of therapy, including the recently published Tailored Antiplatelet Therapy Following PCI (TAILOR-PCI) $[27,28]$. In the primary analysis of this trial, which compared clopidogrel with ticagrelor in patients with loss-of-function alleles only, ticagrelor treatment led to a $34 \%$ reduction in ischemic events, though it missed statistical significance (HR $0.66,95 \%$ CI $0.43-1.02, p=0.06$ ). This, because the trial was powered to detect a very ambitious $50 \%$ reduction in ischemic events [28]. Still, this difference is much larger than the $16 \%$ difference seen in PLATO [3].

A trial that investigated genotype-guided de-escalation was the CYP2C19 Genotype-Guided Antiplatelet Therapy in STEMI Patients-Patient Outcome after Primary PCI (POPular Genetics) trial. It investigated de-escalation from potent $\mathrm{P}_{2} \mathrm{Y}_{12}$ inhibitors to clopidogrel within 1 to 3 days after primary PCI in 2488 patients with ST-elevation myocardial infarction [18]. In patients randomized to the genotype-guided strategy the presence of the CYP2C19*2 and * 3 allele was determined as soon as possible after primary PCI. Non-carriers of these alleles were de-escalated to clopidogrel, while carriers remained on potent platelet inhibitors. Median time from primary PCI to de-escalation was approximately 1.5 days. Patients in the control group received standard treatment with either ticagrelor or prasugrel for 12 Months. The trial found that the genotype-guided group was non-inferior to the standard-treatment group regarding net clinical benefit, defined as all-cause death, myocardial infarction, definite stent thrombosis, stroke, and PLATO major bleeding (5.1\% vs. $5.9 \%$ for genotype-guided and standard treatment respectively, $\mathrm{P}_{\text {non-inferiority }}<0.001, \mathrm{HR} 0.87,95 \% \mathrm{CI} 0.62-1.21$ ). It was also non-inferior regarding the thrombotic outcome, defined as cardiovascular death, myocardial infarction, definite stent thrombosis, and stroke ( $2.7 \%$ vs. $3.3 \%$ for genotype-guided and standard treatment respectively, HR $0.83,95 \%$ CI $0.53-1.31$ ). Furthermore it found that a genotype-guided strategy was superior in reducing combined PLATO major and minor bleedings $(9.8 \%$ vs. $12.5 \%$ for genotype-guided and standard treatment respectively, HR 0.78, 95\% CI 0.61-0.98), which was mainly driven by a reduction in PLATO minor bleedings. Therefore, the genotype-guided therapy proved to be beneficial by reducing bleeding events, while not increasing thrombotic events. An important limitation of the POPular Genetics trial was the much lower than anticipated event rate. Since the non-inferiority margin was fixed $(2 \%)$, the relative margin was much greater than expected. However, similar to the PFT guided group in the TROPICAL-ACS trial [17], patients in the genotype-guided group had numerically less thrombotic and bleeding events than patients in the standard treatment group. Other limitations included the open-label design and that more, though rare, CYP2C19 loss-of-function alleles exist which were not tested in the trial.

\section{Summary}

Based on the currently available research, the European Society of Cardiology (ESC) guidelines provide a class IIb recommendation to use unguided, PFT, or genotyping to guide antithrombotic treatment in a subgroup of ACS patients deemed unsuitable for potent platelet inhibition [29]. An expert consensus paper concerning platelet function and genetic testing to guide $\mathrm{P}_{2} \mathrm{Y}_{12}$ inhibitor treatment in PCI patients was published last year, prior to the results of the POPular Genetics trial. This consensus paper gives some suggestions as to when de-escalation in patients with myocardial infarction could be 
considered and when to escalate $\mathrm{P} 2 \mathrm{Y}_{12}$ inhibitor therapy (Figure 1). In general, de-escalation should be considered in patients with a high bleeding risk (Table 2). This includes prior major bleeding, prior hemorrhagic stroke, anemia, and clinically significant bleeding on dual-antithrombotic therapy [30]. Bleeding risk scores might also be used to help decision making, though this has never been tested in a clinical trial. Furthermore, socio-economic reasons could be a factor in deciding to de-escalate therapy. If opted to de-escalate antithrombotic therapy in a patient, choosing either PFT or genetic testing both have their advantages and disadvantages (Table 3). Ultimately deciding on what strategy to use will depend on the availability of the different tests and assays, the experience and logistics in the hospital, and on the country and healthcare system the hospital is located in.

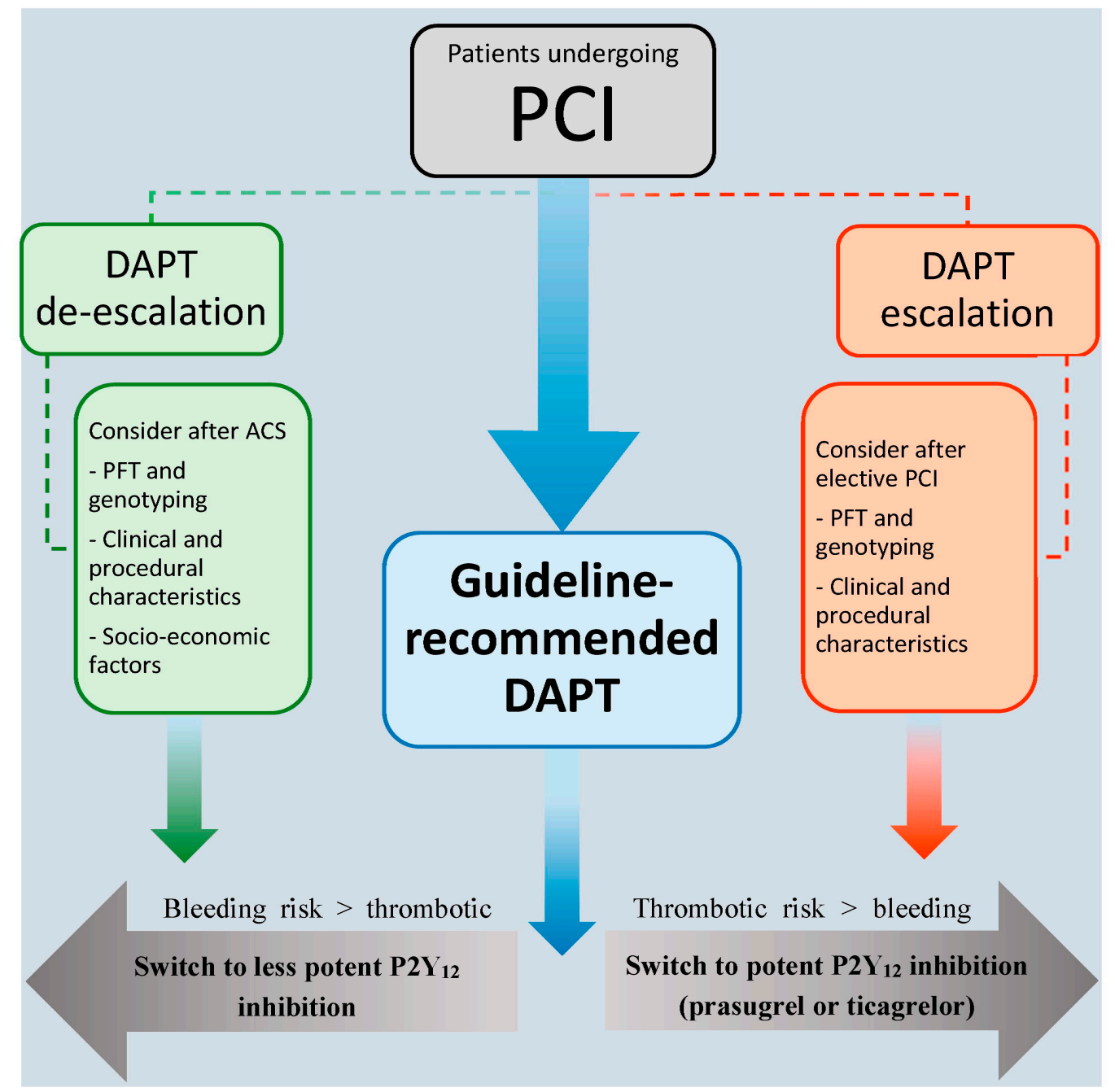

Figure 1. Strategies for dual antiplatelet therapy after PCI. The majority of patients undergoing percutaneous coronary intervention (PCI) should be treated with guideline recommended dual antiplatelet therapy (DAPT) (clopidogrel in elective PCI and ticagrelor or prasugrel in patients with acute coronary syndrome (ACS)). In elective PCI patients, an escalation strategy can be considered in some situations, when the thrombotic risk is higher than the bleeding risk. In ACS patients, de-escalation can be considered when the bleeding risk is higher than the thrombotic risk or for socio-economic considerations. 
Table 2. Variables that could be considered for favoring de-escalation of dual antiplatelet therapy.

\begin{tabular}{c}
\hline Prior Major Bleeding \\
\hline Anemia \\
\hline Clinically Significant Bleeding on Potent P2Y 12 Inhibitors \\
\hline High Bleeding Risk Defined by Bleeding Risk Scores \\
\hline Socio-Economic Factors Favoring the Lower Costs of Clopidogrel \\
\hline Side Effects on Prasugrel And Ticagrelor, Especially Dyspnea on Ticagrelor \\
Need for Triple Treatment Due to New Onset Atrial Fibrillation or Left Ventricular Thrombus \\
After Myocardial Infarction \\
\hline
\end{tabular}

Table 3. Advantages and disadvantages of platelet function and genetic testing.

\begin{tabular}{ccc}
\hline Table Header & Platelet Function Testing & Genotyping \\
\hline Availability of Different Assays & Yes & Yes \\
\hline Availability of Point-Of-Care Systems & Yes & Yes \\
\hline Inter-Assay Variability & Yes & No \\
\hline Variability of Results Over Time & Yes & No \\
\hline Association with Thrombotic Events & Yes & Yes \\
\hline Association with Bleeding Events & Yes & Yes \\
\hline Availability of Clinical Trial Data on Guided Therapy & Yes & Yes \\
\hline Feasibility in Clinical Practice & Yes & Yes \\
\hline Results Influenced by Extra Patient Factors & Yes & No \\
\hline Direct Measure of Response to Therapy & Yes & No \\
\hline $\begin{array}{c}\text { Assessment of Influence of Both Genetic and } \\
\text { Non-Genetic Factors on Platelet Function }\end{array}$ & Yes & No \\
\hline Need to Be Performed While on Treatment & Yes & No \\
\hline Modified and Adapted with Permission from Sibbing Et Al. [30] & \\
\hline
\end{tabular}

\section{How to De-Escalate Antiplatelet Therapy}

After deciding to de-escalate to clopidogrel, it is possible to do this either by giving a loading dose or not. There have not been any randomized trials powered for clinical outcomes investigating this, but an expert consensus paper by Angiolillo et al. gives a recommendation based on pharmacodynamic studies. Whether or not giving a loading dose is based on the timing of de-escalation and what $\mathrm{P} 2 \mathrm{Y}_{12}$ inhibitor is used prior to de-escalation (Figure 2) [31]. When de-escalating in the early phase ( $\leq 30$ days from the index event) a 600 mg loading dose of clopidogrel should be administered $24 \mathrm{~h}$ after the last dose of prasugrel or ticagrelor. In a sub-analysis of the POPular Genetics trial, this method seemed save with no bleeding and thrombotic events in 172 patients who switched to clopidogrel within seven days after STEMI [32]. When de-escalating from ticagrelor to clopidogrel in the late phase ( $>30$ days from the index event) a $600 \mathrm{mg}$ loading dose $24 \mathrm{~h}$ after the last dose of ticagrelor is recommended, while it is not recommended to use a new loading dose when switching from prasugrel to clopidogrel in the late phase. If de-escalating due to bleeding or bleeding concerns, a $75 \mathrm{mg}$ clopidogrel dose could be considered instead of a loading dose irrespective of the phase or initial $\mathrm{P}_{2} \mathrm{Y}_{12}$ inhibitor [31]. 


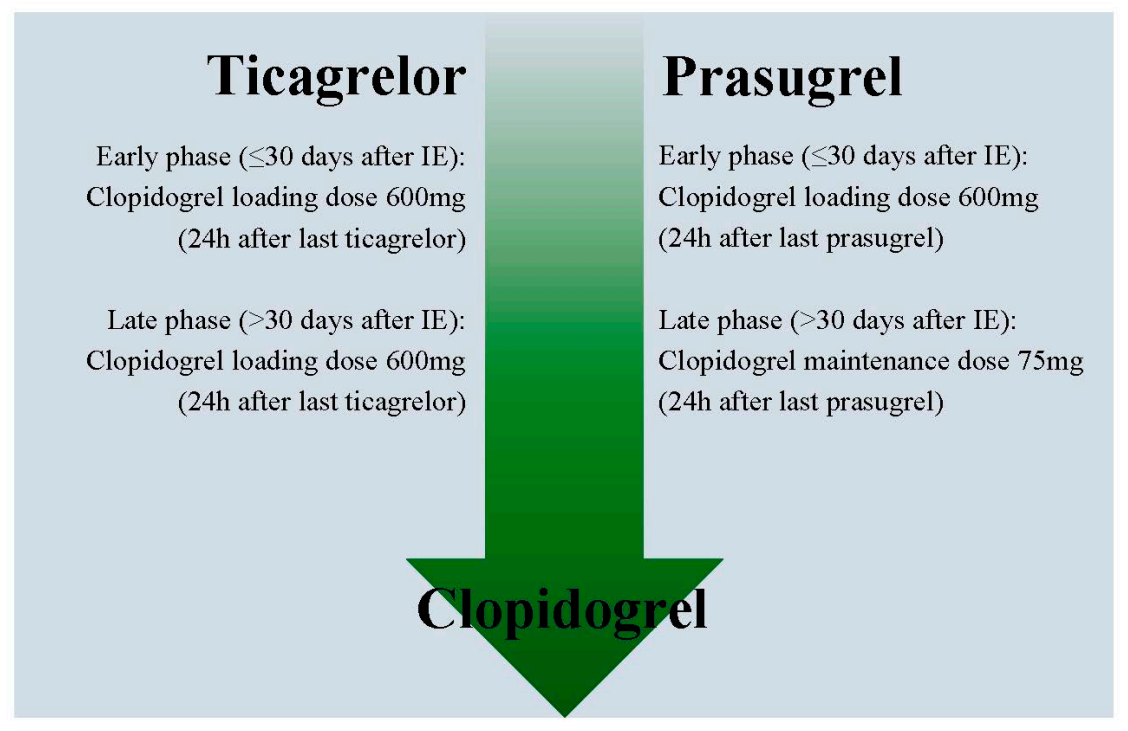

Figure 2. Recommended clopidogrel doses when de-escalating. When de-escalating from ticagrelor or prasugrel to clopidogrel in the early phase ( $\leq 30$ days after the index event), a loading dose of $600 \mathrm{mg}$ should be administered $24 \mathrm{~h}$ after the last dose of the potent $\mathrm{P}_{2} \mathrm{Y}_{12}$ inhibitor. In the late phase $(>30$ days after the index event), a loading dose of $600 \mathrm{mg}$ should only be administered from ticagrelor to clopidogrel, while a maintenance dose of $75 \mathrm{mg}$ should be administered when de-escalating from prasugrel to clopidogrel. If de-escalating due to bleeding or bleeding concerns, a $75 \mathrm{mg}$ clopidogrel dose could be considered instead of a loading dose irrespective of the phase or initial $\mathrm{P}_{2} \mathrm{Y}_{12}$ inhibitor.

\section{Conclusions and Future Perspective}

With a decline in ischemic events in the last decade, focus has shifted more and more towards preventing bleeding complications. In recent years, we have seen a growing body of evidence supporting de-escalation of antithrombotic therapy in patients with ACS who underwent PCI. Current guidelines offer the option to de-escalate in a subset of ACS patients who are not deemed suitable for potent platelet inhibitors. No new randomized data are expected in the near future. However, cost-effectiveness analyses and meta-analyses, including data from the latest randomized trials, might help expand the current recommendation. Subgroup analyses from currently published trials have not consistently identified patient groups that might benefit more from de-escalation. Therefore, for as long as guidelines do not give a higher recommendation to use de-escalation in a broader population, it will be up to the clinician to assess whether a patient could benefit or not.

Author Contributions: D.M.C. and D.S. both contributed to the writing of the manuscript. All authors have read and agreed to the published version of the manuscript.

Funding: No funding was received for this work.

Conflicts of Interest: Claassens has nothing to declare. Sibbing received institutional grants from Roche Diagnostics, Daiichi Sankyo and lecture fees from Bayer AG, Daiichi Sankyo, Sanofi, Roche Diagnostics, Pfizer, and AstraZeneca.

\section{References}

1. Ibanez, B.; James, S.; Agewall, S.; Antunes, M.J.; Bucciarelli-Ducci, C.; Bueno, H.; Caforio, A.L.P.; Crea, F.; Goudevenos, J.A.; Halvorsen, S.; et al. 2017 ESC guidelines for the management of acute myocardial infarction in patients presenting with ST-segment elevation: The task force for the management of acute myocardial infarction in patients presenting with ST-segment elevation of the European Society of Cardiology. Eur. Heart J. 2018, 39, 119-177. [PubMed]

2. Levine, G.N.; Bates, E.R.; Bittl, J.A.; Brindis, R.G.; Fihn, S.D.; Fleisher, L.A.; Granger, C.B.; Lange, R.A.; Mack, M.J.; Mauri, L.; et al. 2016 ACC/AHA Guideline Focused Update on Duration of Dual Antiplatelet Therapy in Patients With Coronary Artery Disease. J. Am. Coll. Cardiol. 2016, 68, 1082-1115. [CrossRef] [PubMed] 
3. Wallentin, L.; Becker, R.C.; Budaj, A.; Cannon, C.P.; Emanuelsson, H.; Held, C.; Horrow, J.; Husted, S.; James, S.; Katus, H.; et al. Ticagrelor versus Clopidogrel in Patients with Acute Coronary Syndromes. N. Engl. J. Med. 2009, 361, 1045-1057. [CrossRef] [PubMed]

4. Wiviott, S.D.; Braunwald, E.; McCabe, C.H.; Montalescot, G.; Ruzyllo, W.; Gottlieb, S.; Neumann, F.-J.; Ardissino, D.; De Servi, S.; Murphy, S.A.; et al. Prasugrel versus Clopidogrel in Patients with Acute Coronary Syndromes. N. Engl. J. Med. 2007, 357, 2001-2015. [CrossRef] [PubMed]

5. Van Werkum, J.; Heestermans, A.; Deneer, V.; Hackeng, C.; Ten Berg, J. Clopidogrel resistance: Fact and fiction. Futur. Cardiol. 2006, 2, 215-228. [CrossRef]

6. Breet, N.J.; Van Werkum, J.W.; Bouman, H.J.; Kelder, J.C.; Ruven, H.J.T.; Bal, E.T.; Deneer, V.H.; Harmsze, A.M.; Van Der Heyden, J.A.S.; Rensing, B.J.W.M.; et al. Comparison of Platelet Function Tests in Predicting Clinical Outcome in Patients Undergoing Coronary Stent Implantation. JAMA 2010, 303, 754. [CrossRef]

7. Claassens, D.M.; Berg, J.M.T. Genotype-guided treatment of oral P2Y12 inhibitors: Where do we stand? Pharmacogenomics 2020, 21, 83-86. [CrossRef]

8. Harmsze, A.M.; Van Werkum, J.W.; Ten Berg, J.M.; Zwart, B.; Bouman, H.J.; Breet, N.J.; van 't Hof, A.W.; Ruven, H.J.; Hackeng, C.M.; Klungel, O.H.; et al. CYP2C19*2 and CYP2C9*3 alleles are associated with stent thrombosis: A case-control study. Eur. Heart J. 2010, 31, 3046-3053. [CrossRef]

9. Angiolillo, D.J.; Fernández-Ortiz, A.; Bernardo, E.; Alfonso, F.; Macaya, C.; Bass, T.A.; Costa, M.A. Variability in Individual Responsiveness to Clopidogrel. J. Am. Coll. Cardiol. 2007, 49, 1505-1516. [CrossRef]

10. Antman, E.M.; Wiviott, S.D.; Murphy, S.A.; Voitk, J.; Hasin, Y.; Widimský, P.; Chandna, H.; Macias, W.; McCabe, C.H.; Braunwald, E. Early and Late Benefits of Prasugrel in Patients with Acute Coronary Syndromes Undergoing Percutaneous Coronary Intervention. J. Am. Coll. Cardiol. 2008, 51, 2028-2033. [CrossRef]

11. Becker, R.C.; Bassand, J.P.; Budaj, A.; Wojdyla, D.M.; James, S.K.; Cornel, J.H.; French, J.; Held, C.; Horrow, J.; Husted, S.; et al. Bleeding complications with the P2Y12 receptor antagonists clopidogrel and ticagrelor in the PLATelet inhibition and patient Outcomes (PLATO) trial. Eur. Heart J. 2011, 32, 2933-2944. [CrossRef] [PubMed]

12. Motovska, Z.; Hlinomaz, O.; Kala, P.; Hromadka, M.; Knot, J.; Varvarovsky, I.; Dusek, J.; Jarkovsky, J.; Miklik, R.; Rokyta, R.; et al. 1-Year Outcomes of Patients Undergoing Primary Angioplasty for Myocardial Infarction Treated with Prasugrel Versus Ticagrelor. J. Am. Coll. Cardiol. 2017, 71, 371-381. [CrossRef] [PubMed]

13. Gimbel, M.; Qaderdan, K.; Willemsen, L.; Hermanides, R.; Bergmeijer, T.; De Vrey, E.; Heestermans, T.; Tjon-Joe Gin, M.; Waalewijn, R.; Hofma, S.; et al. Clopidogrel versus ticagrelor or prasugrel in patients aged 70 years or older with non-ST-elevation acute coronary syndrome (POPular AGE): The randomised, open-label, non-inferiority trial. Lancet 2020, 395, 1374-1381. [CrossRef]

14. Zettler, M.E.; Peterson, E.D.; McCoy, L.A.; Effron, M.B.; Anstrom, K.J.; Henry, T.D.; Baker, B.A.; Messenger, J.C.; Cohen, D.J.; Wang, T.Y.; et al. Switching of adenosine diphosphate receptor inhibitor after hospital discharge among myocardial infarction patients: Insights from the Treatment with Adenosine Diphosphate Receptor Inhibitors: Longitudinal Assessment of Treatment Patterns and Events after Acute Coronary Syndrome (TRANSLATE-ACS) observational study. Am. Hear. J. 2017, 183, 62-68.

15. Angiolillo, D.J.; Patti, G.; Chan, K.T.; Han, Y.; Huang, W.-C.; Yakovlev, A.; Paek, D.; Del Aguila, M.; Girotra, S.; Sibbing, D. De-escalation from ticagrelor to clopidogrel in acute coronary syndrome patients: A systematic review and meta-analysis. J. Thromb. Thrombolysis 2019, 48, 1-10. [CrossRef]

16. Cuisset, T.; Deharo, P.; Quilici, J.; Johnson, T.W.; Deffarges, S.; Bassez, C.; Bonnet, G.; Fourcade, L.; Mouret, J.P.; Lambert, M.; et al. Benefit of switching dual antiplatelet therapy after acute coronary syndrome: The TOPIC (timing of platelet inhibition after acute coronary syndrome) randomized study. Eur. Heart J. 2017, 38, 3070-3078. [CrossRef]

17. Sibbing, D.; Aradi, D.; Jacobshagen, C.; Gross, L.; Trenk, D.; Geisler, T.; Orban, M.; Hadamitzky, M.; Merkely, B.; Kiss, R.G.; et al. Guided de-escalation of antiplatelet treatment in patients with acute coronary syndrome undergoing percutaneous coronary intervention (TROPICAL-ACS): A randomised, open-label, multicentre trial. Lancet 2017, 390, 1747-1757. [CrossRef]

18. Claassens, D.M.F.; Vos, G.J.A.; Bergmeijer, T.O.; Hermanides, R.S.; van ‘t Hof, A.W.J.; van der Harst, P.; Barbato, E.; Morisco, C.; Tjon-Joe Gin, R.M.; Asselbergs, F.W.; et al. AGenotype-guided strategy for oral $\mathrm{P}_{2} \mathrm{Y}_{12}$ inhibitors in primary PCI. N. Engl. J. Med. 2019, 381, 1621-1631. [CrossRef] 
19. Deharo, P.; Quilici, J.; Camoin-Jau, L.; Johnson, T.W.; Bassez, C.; Bonnet, G.; Fernandez, M.; Ibrahim, M.; Suchon, P.; Verdier, V.; et al. Benefit of Switching Dual Antiplatelet Therapy After Acute Coronary Syndrome According to On-Treatment Platelet Reactivity. JACC Cardiovasc. Interv. 2017, 10, 2560-2570. [CrossRef]

20. Kim, H.-S.; Kang, J.; Hwang, D.; Han, J.-K.; Yang, H.-M.; Kang, H.-J.; Koo, B.-K.; Rhew, J.Y.; Chun, K.-J.; Lim, Y.-H.; et al. Prasugrel-based de-escalation of dual antiplatelet therapy after percutaneous coronary intervention in patients with acute coronary syndrome (HOST-REDUCE-POLYTECH-ACS): An open-label, multicentre, non-inferiority randomised trial. Lancet 2020. [CrossRef]

21. De Luca, L.; D’Ascenzo, F.; Tarantini, G.; Saia, F.; Parodi, G.; Varbella, F.; Marchese, A.; De Servi, S.; Berti, S.; Bolognese, L. Incidence and Outcome of Switching of Oral Platelet $\mathrm{P}_{2} \mathrm{Y}_{12}$ Receptor Inhibitors in Patients with Acute Coronary Syndromes Undergoing Percutaneous Coronary Intervention: The SCOPE Registry. EuroIntervention 2017, 13, 459-466. [CrossRef] [PubMed]

22. Janssen, P.W.A.; Bergmeijer, T.O.; Vos, G.-J.A.; Kelder, J.C.; Qaderdan, K.; Godschalk, T.C.; Breet, N.J.; Deneer, V.H.M.; Hackeng, C.M.; Ten Berg, J.M. Tailored $\mathrm{P}_{2} \mathrm{Y}_{12}$ inhibitor treatment in patients undergoing non-urgent PCI-The POPular Risk Score study. Eur. J. Clin. Pharmacol. 2019, 75, 1201-1210. [CrossRef] [PubMed]

23. Price, M.J.; Berger, P.B.; Teirstein, P.S.; Tanguay, J.-F.; Angiolillo, D.J.; Spriggs, D.; Puri, S.; Robbins, M.; Garratt, K.N.; Bertrand, O.F.; et al. Standard- vs High-Dose Clopidogrel Based on Platelet Function Testing After Percutaneous Coronary Intervention. JAMA 2011, 305, 1097-1105. [CrossRef] [PubMed]

24. Collet, J.-P.; Cuisset, T.; Rangé, G.; Cayla, G.; Elhadad, S.; Pouillot, C.; Henry, P.; Motreff, P.; Carrie, D.; Boueri, Z.; et al. Bedside Monitoring to Adjust Antiplatelet Therapy for Coronary Stenting. N. Engl. J. Med. 2012, 367, 2100-2109. [CrossRef]

25. Sibbing, D.; Gross, L.; Trenk, D.; Jacobshagen, C.; Geisler, T.; Hadamitzky, M.; Merkely, B.; Kiss, R.G.; Komócsi, A.; Parma, R.; et al. Age and outcomes following guided de-escalation of antiplatelet treatment in acute coronary syndrome patients undergoing percutaneous coronary intervention: Results from the randomized TROPICAL-ACS trial. Eur. Heart J. 2018, 39, 2749-2758. [CrossRef]

26. Larsen, P.D.; Holley, A.S.; Sasse, A.; Al-Sinan, A.; Fairley, S.; Harding, S.A. Comparison of Multiplatelet and VerifyNow platelet function tests in predicting clinical outcome in patients with acute coronary syndromes. Thromb. Res. 2017, 152, 14-19. [CrossRef]

27. Pereira, N.L.; Farkouh, M.E.; So, D.; Lennon, R.; Geller, N.; Mathew, V.; Bell, M.; Bae, J.; Jeong, M.H.; Chavez, I.; et al. Effect of Genotype-Guided Oral $\mathrm{P}_{2} \mathrm{Y}_{12}$ Inhibitor Selection vs Conventional Clopidogrel Therapy on Ischemic Outcomes After Percutaneous Coronary Intervention: The TAILOR-PCI Randomized Clinical trial. JAMA 2020, 324, 761-771. [CrossRef]

28. Cavallari, L.H.; Lee, C.R.; Beitelshees, A.L.; Cooper-DeHoff, R.M.; Duarte, J.D.; Voora, D.; Kimmel, E.; McDonough, C.W.; Gong, Y.; Dave, C.V.; et al. Multi-site investigation of outcomes with implementation of CYP2C19 genotype-guided antiplatelet therapy after percutaneous coronary intervention. JACC Cardiovasc. Interv. 2018, 11, 181-191. [CrossRef]

29. Collet, J.P.; Thiele, H.; Barbato, E.; Barthélémy, O.; Bauersachs, J.; Bhatt, D.L.; Dendale, P.; Dorobantu, M.; Edvardsen, T.; Folliguet, T.; et al. OUP accepted manuscript. Eur. Heart J. 2020, 00, 1-79. [CrossRef]

30. Sibbing, D.; Aradi, D.; Alexopoulos, D.; Berg, J.T.; Bhatt, D.L.; Bonello, L.; Collet, J.-P.; Cuisset, T.; Franchi, F.; Gross, L.; et al. Updated Expert Consensus Statement on Platelet Function and Genetic Testing for Guiding P2Y12 Receptor Inhibitor Treatment in Percutaneous Coronary Intervention. JACC Cardiovasc. Interv. 2019, 12, 1521-1537. [CrossRef]

31. Angiolillo, D.J.; Rollini, F.; Storey, R.F.; Bhatt, D.L.; James, S.; Schneider, D.J.; Sibbing, D.; So, D.Y.; Trenk, D.; Alexopoulos, D.; et al. International Expert Consensus on Switching Platelet $\mathrm{P}_{2} \mathrm{Y}_{12}$ Receptor-Inhibiting Therapies. Circulation 2017, 136, 1955-1975. [CrossRef] [PubMed]

32. Claassens, D.M.F.; Tavenier, A.H.; Hermanides, R.S.; Vos, G.J.A.; Hinrichs, D.L.; Bergmeijer, T.O.; van 't Hof, A.W.J.; Deneer, V.H.M.; Ten Berg, J.M. Reloading when switching from ticagegrelor or prasugrel to clopidogrel within 7 days after STEMI. JACC Cardiovasc. Interv. 2020, 13, 663-665. [CrossRef] [PubMed]

(C) 2020 by the authors. Licensee MDPI, Basel, Switzerland. This article is an open access article distributed under the terms and conditions of the Creative Commons Attribution (CC BY) license (http://creativecommons.org/licenses/by/4.0/). 